\title{
1
}

\section{HEALTH EQUITY: OVERVIEW, HISTORY, AND KEY CONCEPTS}

\author{
K. BRYANT SMALLEY $\square$ JACOB C. WARREN $\square$ M. ISABEL FERNÁNDEZ
}

\section{LEARNING OBJECTIVES}

- Describe how health is not treated as a fundamental right within the United States

- Discuss the meaning and interrelated nature of health disparities, health equity, and social justice

- Describe how the Healthy People initiative helped to frame the approach to achieving health equity in the United States

- Summarize the ways in which historical factors impact the ability of groups impacted by health disparities to trust the healthcare industry

- Contrast the concepts of equality, equity, and justice

\section{INTRODUCTION}

The field of health equity is broad and ever-expanding. It challenges us all to think about the fundamental nature of health, of society, and ultimately of human rights. Is having equal access to live a healthy life a right or a privilege? Unfortunately, in the United States health is a privilege afforded most readily to those with sufficient socioeconomic status to afford it and enough sociodemographic standing to have equal access to the resources necessary to attain and maintain it. While several states have taken it upon themselves to ensure all residents have access to healthcare, the very patchwork nature of such access proves that health is not considered a right in our country.

Those working in health equity, however, reject this notion, instead believing that all peopleregardless of their cultural and demographic background-should have equal opportunity to live a life of health. As with other rights, however-for example the right to vote or the right to marry-society has intentionally and unintentionally placed and reinforced barriers to health that disproportionately impact minority and other marginalized populations. As discussed in Chapter 2, Prejudice, Discrimination, and Health, issues of discrimination and unequal distribution of resources plague our health system and have significant long-term effects on the health of 
several subpopulations in the United States discussed throughout this text. In attempts to combat these effects, researchers and practitioners have developed a number of models, frameworks, and strategies that are also described in these pages that strive to not only eliminate health disparities, but also to change the fundamental systems such that they create equity in health.

To provide broader context for the remainder of the text's content, in this first chapter we briefly summarize the field at large, provide an abbreviated history of the field of health equity, and conclude with a discussion of the complexities of even naming solutions to these issues.

\section{HEALTH DISPARITIES, HEALTH EQUITY, AND SOCIAL JUSTICE}

\section{Definitions and Origins}

One of the major complexities with the field of health equity is a lack of consistency of definitions, and at times contention among practitioners and researchers regarding terminology. Most agree that, while the concept certainly predated this time, the term "health disparity" came into use in the early 1990s (Braveman, 2014). While there is ongoing debate regarding the definition of the term, it is etymologically drawn from the Latin "dis," meaning "not," and "paritas," meaning "equal." In its purest sense, then, the word "disparity" refers to simple inequality. However, the English word "disparity" is a cognate of the French disparité, meaning unequal in rank or status. This reveals the truer sense typically meant when referring to a health disparity: an inequality in health status or outcomes related to some kind of injustice, oppression, or difference in sociodemographic status. This is in contrast to a simple inequality, which is a difference between groups that may or may not be related to social injustice (e.g., the incidence of skin cancer is higher in Caucasian individuals, but this is attributable to biology rather than injustice; most would not consider this a "true" health disparity).

While generally keeping within that theme, there remain competing definitions that incorporate varying factors under the umbrella of "health disparity." The Centers for Disease Control and Prevention (CDC) has defined "health disparities" as "differences in health outcomes between groups that reflect social inequalities" (Frieden, 2011, p. 1). This definition emphasizes the social nature of disparities, but focuses primarily on outcomes, failing to take into account broader health status (e.g., functioning). The American Public Health Association (APHA, n.d.) has a broader definition of "differences in health status between people that are related to social or demographic factors such as race, gender, income, or geographic region." This definition makes more explicit the relationship with membership in specific demographic groups and broadens the scope to have a focus on health status rather than just health outcomes. While the U.S. Department of Health and Human Services (DHHS) has numerous definitions (e.g., the CDC has its own just described), in its Healthy People 2010 initiative, the agency defined "health disparities" to be "differences that occur by gender, race or ethnicity, education or income, disability, living in rural localities, or sexual orientation" (DHHS, 2000, p. 11). The selection of these specific categories has been criticized as largely arbitrary (Braveman et al., 2011) but has shaped which groups are typically considered when we use the phrase "health disparities." Another criticism is, unlike CDC's definition, both APHA's and Healthy People's definitions remove the focus from the underlying inequities driving the process, instead relating it most directly to the demographic group itself (rather than the injustices associated with being a member of that group). In essence, the APHA and Healthy People are focused on the difference-the health disparity-rather than the 
fundamental processes driving those differences-the issues in health equity. The definition of disparities was subsequently revised in Healthy People 2020 (DHHS, 2010), which used a very inclusive and equity-focused definition of "a particular type of health difference that is closely linked with economic, social, or environmental disadvantage" and explicitly stating that it is related to "characteristics historically linked to discrimination or exclusion" (p. 46). Such definitions-while more inclusive and typically viewed as preferable to the more specific ones just described-still make it somewhat arbitrary as to what someone considers a health disparity. While definitions clearly vary and evolve over time, the core consideration in health disparities is the link to some kind of injustice-the premise being that there is nothing "essential" about the differences, and we as a society are responsible for both their presence and their elimination. To further clarify this distinction, recent movements have embraced the term health inequities rather than health disparities, defined by the American Public Health Association as being "created when barriers prevent individuals and communities from accessing [health] and reaching their full potential" (APHA, n.d.).

\section{SICKLE CELL DISEASE-SIMPLE INEQUALITY OR HEALTH DISPARITY?}

The example of sickle cell disease is often discussed within the context of health disparities, as it is one of very few outcomes whose racial differences can be explained biologically. Sickle cell disease occurs when an individual is homozygous for a gene affecting the production of hemoglobin, which in turn distorts the shape of red blood cells. To be born with sickle cell disease, both of a baby's parents must have had either sickle cell disease (homozygous) or sickle cell trait (heterozygous carriers). Persons of African descent are nearly 25 times as likely to be born with sickle cell trait (Ojodu, Hulihan, Pope, \& Grant, 2014; typically attributed to evolutionary advantages of the anti-malarial properties of sickle cells), creating a direct link between race and the disease. However, does this truly represent a disparity if the difference is related purely to genetics, and not to social inequality? Many argue that sickle cell disease itself is not a disparity; however, there is evidence that there are disparities within sickle cell disease. While it is often thought of as a "Black" disease, sickle cell disease does occur in patients of all races and ethnicities. Studies have shown that when presenting to an emergency room for sickle cell-related emergency, African American patients with sickle cell disease wait $25 \%$ longer to receive services than other patients (Haywood, Tanabe, Naik, Beach, \& Lanzkron, 2013), and half of youth with sickle cell disease report experiencing racist events in medical care settings (Wakefield et al., 2018). Thus, while the presence of sickle cell disease may not be a disparity, there are still disparities and social justice issues within sickle cell disease treatment in need of intervention.

\section{The Emergence of Health Equity}

The field of health disparities has grown tremendously in the past several decades, but in more recent years has been criticized for its focus on outcomes and differences-in essence, dwelling in the problem rather than the solution. The health equity movement grew from this burgeoning 
desire to change the situation itself - in trying to eliminate health disparities, our goal is to achieve health equity. Interestingly, even the concept of health equity has since been broadened. As discussed throughout this text, and in detail in Chapter 3, Health Equity Frameworks and Theories, the vast majority of health disparity issues are now viewed through the lens of social determinants of health - that is, differences in outcomes are rarely accurately attributable to uninfluenced individual behavior (e.g., choosing to smoke), and are more precisely related to differences in factors related to that behavior (e.g., stress levels, poverty, educational attainment, neighborhood environment). To truly eliminate health disparities and thereby achieve health equity, many solutions require a social justice lens. Changing the societal discrimination that elevates baseline stress levels in African Americans would impact much more than just health, but is still essential in achieving health equity for African American populations-thus the path to health equity in many cases lies in social justice. Figure 1.1 illustrates how these three concepts-health disparities, health equity, and social justice-represent different facets of a continuum of concepts.

While historically the field of health equity focused mainly on racial/ethnic differences in health, more recently other groups have been incorporated into the field, such as individuals with diverse sexual orientations and gender identities, individuals with disabilities, and individuals of varying geographic backgrounds (e.g., rural). This expansion has also opened the door for overarching frameworks such as Intersectionality Theory (see Chapter 3, Health Equity Frameworks and Theories), which have begun to explore the ways in which overlapping identities come together to influence health outcomes (e.g., how do the experiences of a straight transgender Latinx woman compare to a bisexual cisgender Asian man, and how do those identities intersect in determining their health?). At the same time, this diversity of focus has led to a literature that is at times fragmented. While the experiences of each group impacted by disparities is unique and worthy of individual study, there are themes that also repeat-for example, the effects of discrimination impact nearly all health disparity groups. One goal of our text is to examine health equity through both lenses-the unique lessons of the experiences of individual health disparity groups (e.g., migrant health), and the broader strategies and convergence of approaches demonstrated to be impactful across multiple populations affected by health disparities (e.g., the importance of cultural humility).

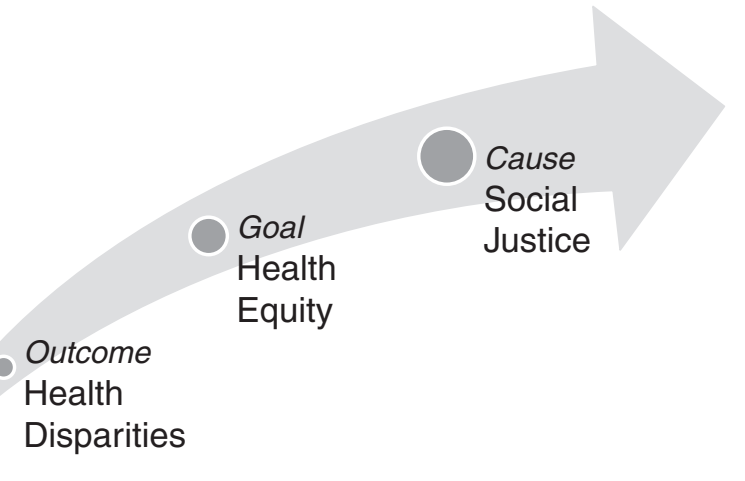

FIGURE 1.1 Relationship between health disparities, health equity, and social justice. 


\section{HISTORICAL CONTEXT OF HEALTH DISPARITIES}

The history of discrimination, marginalization, and direct victimization of minority groups within the medical profession is deep and dark, and is described in more detail in Chapter 2, Prejudice, Discrimination, and Health. Many "modern" medical treatments and even devices can trace their roots to experiments conducted on slaves. In an example summarized by Kathleen Bachynski (2018), in 1894 the Journal of the American Medical Association published a commentary describing how "for the first time in the history of the United States, a public statue has been erected to the memory of a member of the medical profession" ("The statue of Dr. J. Marion Sims in Bryant Park," 1894, p. 689). That physician was Dr. J. Marion Sims, whose likeness initially rested in Bryant Park and was subsequently moved to Central Park (directly across from the New York Academy of Medicine). Sims was lauded in the 1894 article for being elected to the presidency of the American Medical Association in 1875, for founding the first women's hospital in the United States, and for being designated as a Chevalier of the Legion of Honor by Napoleon. Sims additionally invented the precursor of the modern speculum and developed a method to cure vesico-vaginal fistula. What the article fails to mention is the method whereby his techniques were developed-experimentation on slave women without anesthesia in order to increase their ability to both return to "work" in the fields more quickly and to preserve their ability to have more children and thereby grow the slave population in America. Despite its clear reverence for a man who literally took ownership of slave women so he could experiment on them, the statue dedicated to his "brilliant achievements" and "services in the cause of ... mankind" retained its prominent location until it was removed in early 2018.

The story of Sims is emblematic of the ways in which inequities in healthcare itself are deeply rooted and still affecting us today. These stories are not all remote, however. The Tuskegee Syphilis Study, in which the precursor agency to the CDC conducted unconsented research on African American men in which they actively withheld effective treatment for decades, is often cited as a source of modern mistrust of the medical community. Similarly, the oft-ignored history of American eugenics - in which mostly minority patients were sterilized against their will and often even without their knowledge-contributes to the reality that for the majority of our history, the healthcare system has failed to even recognize the fundamental humanity and autonomy of marginalized groups, much less worked to meet their unique health needs in a way to achieve health equity.

While there are many other dark chapters of this history that could be written, there are also shining examples of ways in which people have made substantial contributions to end these injustices and their long-term effects. Dr. John Ruffin, a renowned biologist, took his quest for health equity to the federal government when he became the National Institutes of Health's (NIH's) first Associate Director for Minority programs in 1990. From there, he led the transition of the Office of Minority Programs first into the Office of Research on Minority Health in 1993, then into the National Center on Minority Health and Health Disparities in 2000, and ultimately into the National Institute on Minority Health and Health Disparities in 2010 (NIMHD, 2019), charged with coordinating and overseeing the NIH's investments in minority health and health disparities research. The impact of his work to institutionalize the importance of health disparities throughout not only the NIH, but also the federal government at large, is incalculable and laid the groundwork for much of the research described throughout this text. 
TABLE 1.1 Evolution of Equity-Focused Goals in the Healthy People Initiative

\begin{tabular}{|l|l|}
\hline ITERATION & STATED EQUITY-FOCUSED GOAL(S) \\
\hline Healthy People 2000 & None \\
\hline Healthy People 2010 & $\begin{array}{l}\text { Two goals, including: } \\
\text { Eliminate health disparities }\end{array}$ \\
\hline Healthy People 2020 & $\begin{array}{l}\text { Four goals, including: } \\
\text { Achieve health equity, eliminate disparities, and improve the } \\
\text { health of all groups }\end{array}$ \\
\hline $\begin{array}{l}\text { Feople 2030 goals, including: } \\
\text { Eliminate health disparities, achieve health equity, and attain } \\
\text { health literacy to improve the health and well-being of all } \\
\text { Create social, physical, and economic environments that } \\
\text { promote attaining full potential for health and well-being for all }\end{array}$ \\
\hline
\end{tabular}

Another important turning point in the federal recognition of health disparities was the second iteration of the Healthy People initiative. First launched in 1990, Healthy People 2000 laid out the U.S. Department of Health and Human Services' roadmap for improving the health of Americans by the turn of the century. The plan consisted of 22 priority areas determined to be the most important components of achieving a healthy America. This helped to shape HHS policies and funding decisions for a decade, until it was revised and updated into Healthy People 2010 in the year 2000. Healthy People 2010 marked an important turning point in the field of health disparities, as the initiative had two overarching goals, one of which was to eliminate health disparities. This directed much-needed federal attention to the emerging field of health disparities research, and provided the impetus for federal agencies to begin prioritizing health disparities research in ways not previously done. Reflecting the growth within the field, Healthy People 2020 (released in 2010) incorporated into its four overarching goals the target of achieving health equity, partially shifting the national attention from just eliminating disparities to truly focusing on achieving equity itself. While Healthy People 2030 was still in the process of being finalized at the time of publication of this book, preliminary draft goals include not only a statement of the need to achieve health equity, but also the specific prioritization of methods to do so: a focus both on health literacy and on creating "social, physical, and economic environments that promote attaining full potential for health and well-being for all." The evolution of these goals is summarized in Table 1.1.

\section{EQUALITY, EQUITY, AND JUSTICE}

As we discuss the overarching goal for this body of work-to achieve health equity-there remains an issue with consistency of message. Part of this has to deal with the related, but distinct nature of equality, equity, and justice. While often used interchangeably, "equality" and "equity" are not the same. The concept of equality is ensuring that everyone is allocated equal access to a certain resource, whereas the concept of equity is ensuring that everyone has an equal outcome. Consider an example of the allocation of resources to public health districts. Equality would hold that funding should be apportioned based upon population size-for instance, an urban 
center of 250,000 residents should receive \$25 million in the same way that a rural area of 250,000 residents should receive $\$ 25$ million-each resident resulting in a $\$ 100$ budgetary allocation. Such an approach, however, ignores the structural realities that urban and rural areas are different. The catchment area for the 250,000 urban residents may be less than 100 square miles, whereas the rural catchment area may be thousands of square miles. This geographic factor alone is enough to highlight that the increased need of rural residents (in this case based just upon staff travel distances) merits an increase in allocation of funds if the goal truly is to reach comparable outcomes (i.e., equity). In essence, achieving equity requires providing strategic support where it is most needed, which may involve "unequal" distribution of resources in order to actually achieve an equitable outcome.

A final perspective focuses on justice. Fundamentally, one major reason that rural residents would need additional transportation support to reach services is the lack of public transportation available in rural areas. If public transportation were to be put into place, then the additional allocation of resources would no longer be needed. This is the work of justice-to remove whatever fundamental barrier exists that is leading to the inequity in the first place. This is often easier said than done, of course, but the work of social justice counteracts the need to provide unequal resources (which often makes taxpayers and legislators very uncomfortable, despite its essential nature to achieve equity).

A popular visual representation of the interplay of equality, equity, and justice depicts three individuals attempting to see over a fence at a baseball game (see Figure 1.2). The three individuals are of differing heights (representing different levels of need), yet all three are being treated equally in panel 1 -each has received one box to help them see over the fence. At this level, one individual has more than adequate clearance, but one remains unable to see the game. In the second panel, equity has been achieved by reassigning one box from the first person to the third; to have equal outcomes, it was necessary to have strategic, albeit unequal, distribution of resources to overcome the higher level of need. A justice lens, however, does not focus on how to get everyone where they can see over the fence, but rather focuses on removing the barrier itself. In the third panel, the fence itself has been removed, allowing for the boxes to metaphorically be moved to a new issue that needs resolution. Equality therefore treats everyone the same, equity treats

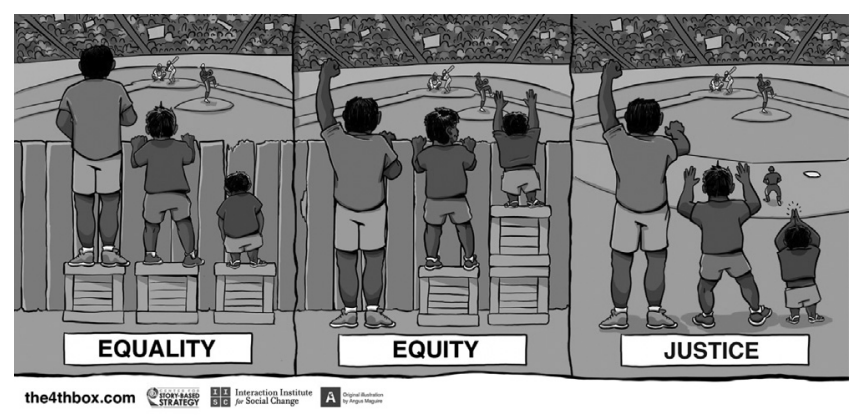

FIGURE 1.2 Common representation of equality, equity, and justice.

SOURCE: Reproduced with permission from Center for Story-Based Strategy. (n.d.). \#the4thBox. Retrieved from https://www.storybasedstrategy.org/the4thbox 
individuals in a way necessary to achieve equal outcomes, and justice removes the fundamental barriers in place that led to the disparity in the first place.

While variations of this image are very commonly used to facilitate discussions of equality, equity, and justice, there are problems with the way it visually depicts the differences in needs between groups. As drawn, there is a fundamental difference between the individuals that is leading to the need for equity and justice - the height of the individual. In reality, the differences we see in health disparities are not the product of individual characteristics of the group, but rather relate to the sociocultural context in which individuals find themselves. An alternate version has been developed that more fully depicts the reality of inequities-that different groups do not start from the same position of advantage, and equity efforts are required to counteract these situational differences (Kuttner, 2016). In these alternate versions, the concept of equality and equity are depicted by showing three individuals of equal height but standing upon unequal ground and blocked by an uneven fence. This places some individuals at higher ground with a lower fence, and some individuals at lower ground with a higher fence. These variations help to reinforce that issues with equity are not due to something fundamentally different in the people themselves; rather, it is related to the situation and environment in which they find themselves.

\section{CONCLUSION}

The fundamental inequities in health that occur between sociodemographic groups in the U.S. represent some of the darkest aspects of our culture, and yet the field of health equity is strikingly new. Ultimately grounded in a historical context of racism, discrimination, injustice, disadvantage, and privilege, it is easy to become overwhelmed with the systemic nature of the issues that must be addressed to truly achieve health equity. Despite this, every day an army of community members and professionals work to do just that-change a system that has so deeply entrenched inequities into our daily lives that it was not until the 1990s that the federal government began to acknowledge the need for change. The work is hard, and at times feels painfully slow, but at the same time, it is some of the most important work being done in our nation.

Our hope for this text is that it will provide not only a historical and descriptive perspective on how we have reached this point, but also clear examples of successes and strategies that can be implemented to address the many concerns identified in its pages. This solutions-focused approach permeates the text, and we hope will inspire you to begin or continue critical work in these areas.

\section{DISCUSSION QUESTIONS}

- How would a movement toward universal health insurance (e.g., Medicare-for-All) not fully solve issues related to inequities in access to healthcare?

- Consider the case of deaths due to diabetes, which are more common among African American women than other demographic groups. How would you describe the disparity, the health equity goal, and a related social justice issue critical in achieving equity in this area? 
- How have the evolving Healthy People goals mirrored the evolving field of health disparities and health equity?

- It is well established that minority groups are under-represented in clinical trials research. Describe structural and historical issues that contribute to this underrepresentation.

- Does inequality necessarily translate into inequity? What are the ways to achieve equity even without achieving equality?

\section{REFERENCES}

American Public Health Association. (n.d.). Health equity. Retrieved from https://www.apha.org/topics -and-issues/health-equity

Bachynski, K. (2018, June 4). American medicine was built on the backs of slaves. And it still affects how doctors treat patients today. Washington Post. Retrieved from https://www.washingtonpost.com/news/ made-by-history/wp/2018/06/04/american-medicine-was-built-on-the-backs-of-slaves-and-it-stillaffects-how-doctors-treat-patients-today

Braveman, P. (2014). What are health disparities and health equity? We need to be clear. Public Health Reports, 129(1 Suppl. 2), 5-8. doi:10.1177/00333549141291S203

Braveman, P. A., Kumanyika, S., Fielding, J., LaVeist, T., Borrell, L. N., Manderscheid, R., \& Troutman, A. (2011). Health disparities and health equity: The issue is justice. American Journal of Public Health, 101(S1), S149-S155. doi:10.2105/AJPH.2010.300062

Center for Story-Based Strategy. (n.d.). \#the4thBox. Retrieved from https://www.storybasedstrategy.org/ the4thbox

Frieden, T. R. (2011). Foreword to CDC Health Disparities and Inequalities Report-United States, 2011. Morbidity and Mortality Weekly Report, 60(S1), 1. Retrieved from https://www.cdc.gov/mmwr/pdf/other/ su6001.pdf

Haywood, C., Jr., Tanabe, P., Naik, R., Beach, M. C., \& Lanzkron, S. (2013). The impact of race and disease on sickle cell patient wait times in the emergency department. American Journal of Emergency Medicine, 31(4), 651-656. doi:10.1016/j.ajem.2012.11.005

Kuttner, P. (2016). The problem with that equity vs. equality graphic you're using. Retrieved from http:// culturalorganizing.org/the-problem-with-that-equity-vs-equality-graphic

National Institute on Minority Health and Health Disparities. (2019). History. Retrieved from https://www .nimhd.nih.gov/about/overview/history

Ojodu, J., Hulihan, M. M., Pope, S. N., \& Grant, A. M. (2014). Incidence of sickle cell trait-United States, 2010. Morbidity and Mortality Weekly Report, 63(49), 1155-1158. Retrieved from https://www.cdc.gov/ $\mathrm{mmWr} /$ preview/mmwrhtml/mm6349a3.htm

The statue of Dr. J. Marion Sims in Bryant Park. (1894). Journal of the American Medical Association, 23(18), 689-690. doi:10.1001/jama.1894.02421230029003

U.S. Department of Health and Human Services. (2000). Healthy People 2010: Understanding and improving health. Washington, DC: US Government Printing Office. Retrieved from https://www.healthypeople. gov/2010/Document/pdf/uih/2010uih.pdf

U.S. Department of Health and Human Services. (2010). Phase I report: Recommendations for the framework and format of Healthy People 2020. Retrieved from http://www.healthypeople.gov/sites/default/files/ PhaseI_0.pdf

Wakefield, E. O., Pantaleao, A., Popp, J. M., Dale, L. P., Santanelli, J. P., Litt, M. D., \& Zempsky, W. T. (2018). Describing perceived racial bias among youth with sickle cell disease. Journal of Pediatric Psychology, 43(7), 779-788. doi:10.1093/jpepsy/jsy015 